\title{
ISSR as new markers for genetic characterization and evaluation of relationships among phytoplankton
}

\author{
Benjamin Bornet ${ }^{1, *}$ Elisabeth Antoine ${ }^{1}$, Michèle Bardouil ${ }^{1}$ and Claire Marcaillou-Le Baut ${ }^{1}$ \\ ${ }^{1}$ Laboratoire Phycotoxines et Nuisances, DEL-MP-PN, IFREMER, rue de I"Ile d"Yeu, BP 21105, 44311 NANTES \\ Cedex 3, France. \\ *: Corresponding author : bbornet@wanadoo.fr
}

\begin{abstract}
Abstract In order to increase the molecular tools and markers needed for the identification of phytoplankton species, the inter simple sequence repeat (ISSR) fingerprinting was adapted to micro-algae and its use in genetic analysis was demonstrated. Twelve strains, 6 Alexandrium, 4 Pseudo-nitzschia, 1 Skeletonema and 1 Tetraselmis were analysed for the first time with ISSR amplifications. The patterns were highly polymorphic and very reproducible. The 6 primers gave 223 polymorphic markers that clearly and easily distinguished all 12 strains (mainly toxic ones) and gave 187 polymorphic markers among the Alexandrium and the Pseudo-nitzschia species. ISSR amplifications also indicated a large occurrence of simple sequence repeat (SSR) in phytoplankton genomes, especially in Pseudo-nitzschia, and show their usefulness to cluster intra and inter species. ISSR markers were found to be good markers for genetic characterization and diversity study and led to consider them as new tools for the survey of phytoplankton.
\end{abstract}

Keywords: Alexandrium - fingerprints - genetic characterization and diversity - ISSR - Pseudonitzschia - Skeletonema - Tetraselmis 


\section{Abbreviations}

DGGE, Denatured Gradient Gel Electrophoresis; HMA, Heteroduplex Mobility Assay; ITS, Internal Transcribed Spacer, LSU, Large Sub-Unit; RAPD, Random Amplified Polymorphic DNA; RFLP-PCR, Restriction Fragment Length Polymorphism-Polymerase Chain Reaction; SSCP, Single Strand Conformation Polymorphism; SSU, Small Sub-Unit.

\section{Introduction}

Phytoplankton represents a major component of marine ecosystem, with around 3400 to 4000 species including toxic strains thus needing monitoring program to prevent economical and health consequences. Identification of phytoplankton is currently based on morphological characterization (light and electronic microscopy), which is time consuming, difficult and observer dependent. As a consequence, the development of new reliable and efficient tools based on molecular analysis has been increasing for the last 15 years because species identification is a critical step. Molecular biology techniques are powerful methods and good candidates because of their consistency independently of environmental parameters and developmental stages. During the last decade, molecular characterization and genetic relationships were mainly based on the analysis of rRNA genes: sequence comparison of SSU, LSU and ITS regions, RFLP-PCR and nucleic acid hybridization technologies (e.g. Scholin et al.1994, Walsh et al. 1998, Guillou et al. 2002). More recently, some studies have used the heterogeneity of a few characteristic genes: $r b c L$ and $r b c S$ or $p s b A$ (Chesnick et al. 1996, Takishita and Uchida 1999) or reported the use of molecular markers: RAPD, SSCP, DGGE and HMA (Adachi et al. 1997, Murayama-Kayano et al. 1998, Bolch et al. 1999, Uribe et al. 1999, Oldach et al. 2000, Coyne et al. 2001). These studies were able to characterize some species but lacked polymorphism to identify all the tested species.

In higher plants or animals, Inter Simple Sequence Repeat or ISSR (Zietkiewicz et al. 1994) markers are more and more in demand, because they are known to be abundant, very reproducible, highly polymorphic, highly informative and quick to use (Zietkiewicz et al. 1994, Bornet and Branchard 2001, Bornet et al. 2002). ISSR uses the presence through out the genome of Simple Sequence Repeats (SSR) which are ubiquitous, abundant and highly polymorphic tandem repeat motifs composed of 1 to 7 nucleotides. A unique PCR primer composed of a few SSR repeats (with or without anchored end) was used to amplify DNA sequences between two inverted SSR composed of the same units and spaced out by less than around $4 \mathrm{Kbp}$. Neither sequence information nor prior genetic studies were required for these analyses, unlike for SSR markers. So far, ISSR has not been used to study phytoplankton although it has the potential to fill up the need of more polymorphic tools to distinguish micro-algae. The aim of the study 
esported here was to evaluate the use of ISSR markers to characterize and to estimate genetic diversity between 12 cultured strains: 6, 4, 1 and 1 Alexandrium, Pseudonitzschia, Skeletonema and Tetraselmis genera, respectively.

\section{Materials and methods}

Micro-algal cells and cultures

Twelve species of micro-algae were used: Alexandrium [minutum (France), A. fundyense (Canada), A.tamarense (UK and Japan) and A. catenella (France and Spain)], Pseudonitzschia [pseudodelicatisima (France), P. pungens (Spain), P. multiseries (France) and P. fraudulenta (Spain)], Skeletonema costatum (France) and Tetraselmis suesica (UK). Monoclonal cultures were maintained, in ESP medium of Provasoli (1968) and f/2 medium (Guillard \& Ryther,1962) for Alexandrium, Skeletonema and Tetraselmis or in ESP-K modified medium (J. Fresnel, Université de Caen, France, pers. comm.) for Pseudonitzschia. All cultures were grown under controlled conditions: $16^{\circ} \mathrm{C}, 12 / 12 \mathrm{~h}$ light/dark photoperiod and $50+/-4 \mu \mathrm{E} \mathrm{m}^{-2} \mathrm{~s}^{-1}$ light intensity.

\section{DNA extraction}

Micro-algae were grown to the mid exponential phase and cells were harvested by centrifugation at $6000 \mathrm{~g}$ for $10 \mathrm{~min}$. Cells were re-suspended in $1 \mathrm{ml}$ of CTAB extraction buffer $(100 \mathrm{mM}$ Tris [pH 8.0], 1.4 M NaCl, 20 mM EDTA [pH 8.0], 0.2\% $\beta$-mercaptoethanol, 1\% SDS, $180 \mu \mathrm{g}$ proteinase $\mathrm{K}, 2 \% \mathrm{CTAB}$ ) and heated at $65^{\circ} \mathrm{C}$ for $90 \mathrm{~min}$. DNA was purified successively by one chloroform:isoamyl alcohol (24:1), one phenol:chloroform:isoamyl alcohol (12:12:1) and one chloroform:isoamyl alcohol (24:1) extractions. After precipitation with $0.6 \mathrm{ml}$ of cold isopropanol, the DNA pellet was washed with ethanol (70\%)-ammonium acetate (10 $\mathrm{mM}) \mathrm{mix}$ and ethanol (70\%). DNA was dissolved in TE buffer (10 mM Tris [pH 8.0], 1 mM EDTA [pH 8.0]) and RNA was digested using $10 \mathrm{ng}$ of Rnase (Promega, USA). The DNA concentrations were calculated with a fluorometer (DyNA Quant 200, Hoefler, Amersham Biosciences, USA) using bisbenzimide (Amersham Biosciences, USA) as the fluorescent dye.

\section{ISSR amplifications}

Five primers without anchored end and one with a 5'-anchored end, were tested using specific and optimal annealing temperatures (table 1). ISSR-PCR amplifications and analyses were those described by Bornet and Branchard (2001) with the following modifications: the first denaturation step was increased to $6 \mathrm{~min}$. and the number of cycles were increased to 32 , the 
primer and dNTP concentrations were increased to $6 \mu \mathrm{M}$ and $400 \mu \mathrm{M}$, respectively. PCR was performed in triplicate using a Mastercycler apparatus (Eppendorf, Germany).

Table 1. List of the six primers used to amplify ISSR markers from phytoplankton DNA.

\begin{tabular}{llll}
\hline Primer & $\mathrm{T}_{\mathrm{A}}\left({ }^{\circ} \mathrm{C}\right)$ & $\begin{array}{l}\text { Range of amplified } \\
\text { fragments }\end{array}$ & $\begin{array}{l}\text { Total number of } \\
\text { selected fragments }\end{array}$ \\
\hline$(\mathrm{CCA})_{5}$ & 57 & $200-2200 \mathrm{bp}$ & 39 \\
$(\mathrm{CAA})_{5}$ & 52 & $180-2500 \mathrm{bp}$ & 37 \\
$(\mathrm{CAG})_{5}$ & 60 & $100-2300 \mathrm{bp}$ & 43 \\
$(\mathrm{ATG})_{5}$ & 45 & $100-2550 \mathrm{bp}$ & 44 \\
$(\mathrm{GACA})_{4}$ & 52 & $175-1850 \mathrm{bp}$ & 37 \\
$\mathrm{GTC}(\mathrm{CT})_{8}$ & 55 & $200-1950 \mathrm{bp}$ & 23 \\
\hline
\end{tabular}

\section{Data analysis}

ISSR patterns were compared and markers were scored twice as being present or absent using ImageMaster 1D software (Amersham Biosciences). Only well separated bands with high intensity were selected as markers. Pairwise comparisons were calculated using Jaccard's coefficient (Jaccard. 1901). The similarity values found were used to generate a consensus tree using the Unweighted Pair Group Method Analysis (UPGMA), analyses were performed with NTSYSpc version 2.0 (Rohlf 1998). ISSR data were also subjected to genetic analysis using POPGENE 1.32 software (http://www.ualberta.ca/ fyeh).

\section{Results}

Six primers were used: four non-anchored tri-nucleotides, one non-anchored tetra-nucleotide and one anchored di-nucleotide (Table 1). PCR amplifications were performed in triplicate and from different DNA extractions for each strain and the results obtained for a same specie gave identical electrophoresis patterns, i.e. ISSR fingerprints. Each primer gave rich and clear patterns with selected bands from 100 to $2500 \mathrm{bp}$. Representative ISSR fingerprints obtained with primer $(\mathrm{ATG})_{5}$ are shown in Figure 1. A total of 223 bands of high intensity and well separated were selected as markers. All the ISSR markers were polymorphic among the 12 strains. The average of amplified polymorphic markers was of 37 per primer, with a minimum of 23 and a maximum of 44 (Figure 1). Primer (CAA) 5 gave no or one band with Alexandrium DNA. No significant difference of the number of amplified bands was observed with the other primers among the 
Alexandrium and Pseudonitzschia genomes (Table 2). Among the 223 markers, 187 were amplified only in Alexandrium or Pseudonitzschia and 42 were common to these two genera. Forty four ISSR markers were amplified in Alexandrium strains (one or more strains) only and 101 in Pseudonitzschia strains (one or more strains) only (Table 2). ISSR markers clearly and easily distinguish all the tested species and also discriminate between toxic/non toxic or geographical origins of strains from the same species.

The similarity values of the phenogram (Figure 2) obtained from 223 ISSR markers ranged from 0.0546 to 0.2143 and the cophenetic coefficient was 0.97 . Two main distinct clusters were observed and diverged at 0.0546 phenon level. The first one, including the seven strains of Alexandrium (dinoflagellate), can be subdivided in two groups: the A. minutum, A. fundyense, A. tamarense (Japan and U.K.) group and the A. catenella (France and Spain) group, these groups being separated at a similarity level of 0.1000 . The second cluster, included the last six strains: four Pseudonitzschia, one Tetraselmis and one Skeletonema, which corresponded to five diatoms and 1 flagellate. Pseudonitzschia species have been clustered into two groups composed of $P$. pungens/P. fraudulenta and $P$. pseudodelicatisima/P. multiseries respectively.

Table 2. Mean genetic characteristics of Alexandrium and Pseudonitzschia populations from ISSR data obtained with the software Popgene 1.32, numerical data in italics correspond to standard deviation.

\begin{tabular}{|c|c|c|c|c|c|c|c|c|c|}
\hline Analyse population & $\mathrm{Nt}$ & Ns & $\mathrm{Ne}$ & $\mathrm{h}$ & I & $\mathrm{Ht}$ & Hs & Gst & $\mathrm{Nm}$ \\
\hline \multirow{2}{*}{ Alexandrium } & \multirow{2}{*}{86} & \multirow{2}{*}{44} & 1.299 & 0.215 & 0.365 & \multirow{2}{*}{ - } & \multirow{2}{*}{ - } & \multirow{2}{*}{-} & \multirow{2}{*}{-} \\
\hline & & & 0.203 & 0.097 & 0.117 & & & & \\
\hline \multirow{2}{*}{ Pseudonitzschia } & \multirow{2}{*}{142} & \multirow{2}{*}{101} & 1.438 & 0.290 & 0.4604 & \multirow{2}{*}{-} & \multirow{2}{*}{-} & \multirow{2}{*}{-} & \multirow{2}{*}{-} \\
\hline & & & 0.223 & 0.093 & 0.0106 & & & & \\
\hline \multirow{2}{*}{$\begin{array}{l}\text { Alexandrium and } \\
\text { Pseudonitzschia }\end{array}$} & \multirow{2}{*}{187} & \multirow{2}{*}{42} & 1.215 & 0.166 & 0.298 & 0.179 & 0.159 & \multirow{2}{*}{0.1084} & \multirow{2}{*}{4.1139} \\
\hline & & & 0.153 & 0.088 & 0.117 & 0.008 & 0.005 & & \\
\hline
\end{tabular}

$\mathrm{P}=$ percentage of polymorphism

$\mathrm{Nt}=$ Number total of makers (100\% polymorphic in this study)

Ns $=$ Number of specific makers amplified only in the genus (100\% polymorphic in this study)

$\mathrm{Ne}=$ effective number of alleles (Kimura and Craw, 1964)

$\mathrm{h}=$ Nei's (1973) gene diversity

I = Shannon's information index (Lewontin, 1972)

Figure 1. ISSR patterns of the 12 strains of phytoplankton (Dinoflagellates, Flagellate, Diatoms) amplified with primer $(\mathrm{ATG})_{5}$. 


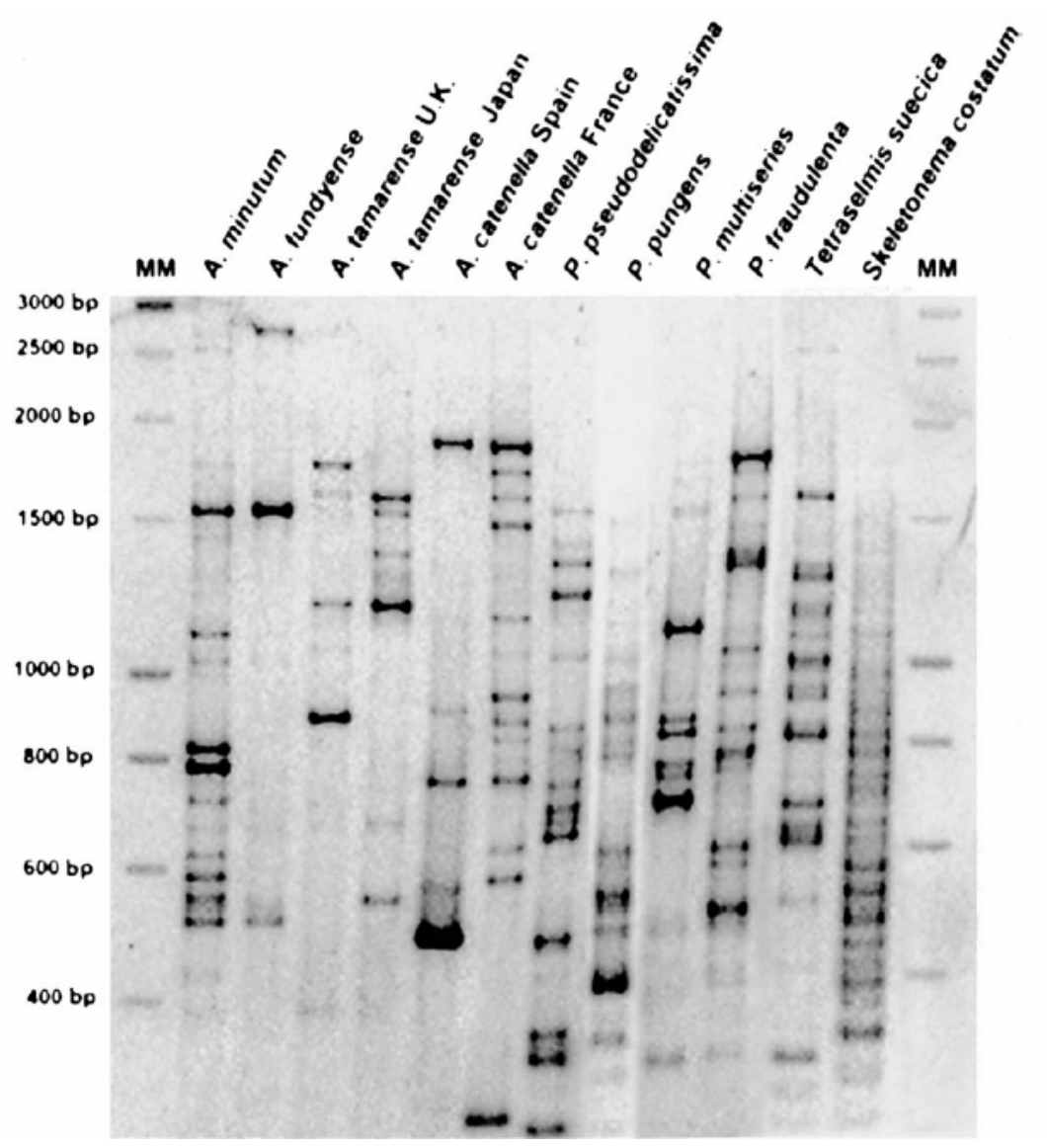

Figure 1. ISSR patterns of the 12 strains of phytoplankton (dinoflagellates, flagellate, diatoms) amplified with primer (ATG)5.

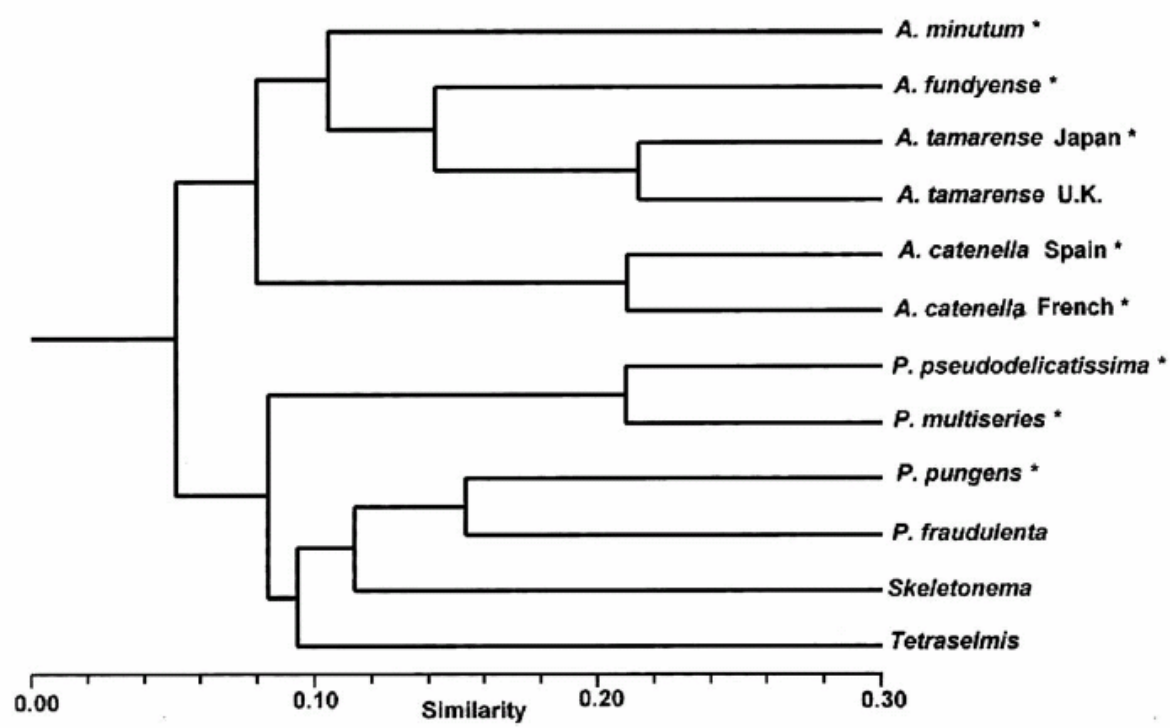

Figure 2. Consensus cluster analysis of the 12 cultivated strains of toxic $\left(^{*}\right)$ and non-toxic phytoplankton using ISSR fingerprints data (223 polymorphic markers) from a Jaccard similarity matrix and the UPGMA method. 


\section{Discussion}

ISSR fingerprints were previously amplified, with more or less success, in animal and higher plants using different approaches. In this study, the use of ISSR fingerprints, described by Bornet and Branchard (2001), needed some slight modifications to give optimal patterns in phytoplankton because of the genetic and chemical characteristics of micro-algae. Six primers were selected and have shown the ability of ISSR markers to provide robust, complete and polymorphic fingerprints among micro-algal species (Table 1 and Figure 1). Primer (ATG) proved to be the best one due to the sharpness of its patterns and the high number of polymorphic markers provided. ISSR amplification denoted a very low abundance of CAA repeats in the Alexandrium genomes and an unequal abundance of CCA, CAG, ATG, GACA and CT repeats in Alexandrium and Pseudonitzschia genomes. SSR were less abundant in Alexandrium than in Pseudonitzschia.

ISSR fingerprints clearly distinguished all the tested species. They allowed identification from genus level to geographical species level and allowed to separate toxic from non toxic strains of the same species. Considering Alexandrium and Pseudonitzschia strains as forming two populations, ISSR markers were more abundant and homogenous within Pseudonitzschia. However, their efficiency for genetic population purpose were quite identical within Pseudonitzschia and Alexandrium (especially primer (CAA) $)_{5}$ and (GACA) $)_{4}$ ), even if less strains were used for Pseudonitzschia (Table 2). When compared to RAPD, another multi-loci and PCR-based method, ISSR amplifications gave more markers and showed a higher level of polymorphism between phytoplankton species (Adachi et al. 1997, Murayama-Kayano et al. 1998, Bolch et al. 1999). These observations are in agreement with many studies showing the higher reproducibility and efficiency of ISSR markers (e.g. Nagaoka and Ogihara 1997, Devarumath et al. 2002, Galvan et al. 2003). This confirms the superiority of ISSR over RAPD to study phytoplankton species. ISSR technique is also more economical than other molecular marker fingerprinting methods (RAPD, RFLP, AFLP, SSCP or SSR).

ISSR fingerprints appeared to be a useful, quick and inexpensive molecular tool to solve the problems of morphological identification and strain characterization of toxic phytoplankton species especially encountered for Pseudonitzschia or Alexandrium species. For example, the identification of different strains from the same species of Alexandrium was impossible or very difficult based on optical observations. If $A$. minutum can be easily distinguished from $A$. tamarense and $A$. catenella due to their significant cell sizes variation but $A$. tamarense and $A$. catenella species belonging to the "tamarense complex" (A. tamarense, A. catenella and A. fundyense) need thecal plate dissection and microscope examination to be distinguished. Morphological observations also show that A. catenella and A. fundyense are more closely 
related to each other than to A. tamarense (Walsh et al. 1998). Moreover molecular studies species based on rDNA (either by RFLP analysis or by sequencing) have led to more or less specific genetic profiles and sequence signatures (Scholin et al. 1994, Walsh et al. 1998, Guillou et al. 2002), no clear identification of the species from the "tamarense complex" has been achieved. ISSR fingerprints, amplified with each of the 6 primers, were able to distinguish all the strains and to discriminate between the two strains A. catenella and A. tamarense, including the toxic one from Japan and the non-toxic one from U.K. ISSR markers described in this study also proved to be powerful tools for the identification of cultured strains of Pseudonitzschia. For example, Scholin et al. (1999) easily detected P. australis and P. pseudodelicatissima by RNA probing analysis but they had some difficulties to identify $P$. multiseries and failed to identify $P$. pungens. All species of Pseudonitzschia were quickly and easily characterized with each primer.

The ISSR markers were used to evaluate their efficiency to study genetic relationships among phytoplankton. Two main groups were observed and few differences in the clustering have been observed between ISSR data and rDNA data: for example, Scholin et al. (1994) have observed more similarities between $A$. tamarense and $A$. fundyense than between $A$. tamarense and A. catenella with the exception of A. tamarense from Western Europe. They also have shown a high divergence between $A$. minutum and A. tamarense/A. fundyense/A. catenella. Walsh et al. (1998) have not observed differences between A. tamarense and A. fundyense and found more similarity with A. catenella than with A. minutum. Considering Pseudonitzschia species, Lundholm et al. (2002) have grouped P. pseudodelicatisima with $P$. fraudulenta and $P$. multiseries with $P$. pungens. This can easily be explained by the different targeted regions and the high polymorphism level of scanning regions by the ISSR analysis.

ISSR were used for the first time to characterize and to evaluate the genetic diversity within some marine phytoplankton including species causing toxic harmful blooms. ISSR-PCR gave complete, very reliable, reproducible and highly polymorphic fingerprints between phytoplankton species. This study showed the usefulness of ISSR fingerprints over rDNA data for phytoplankton analyses. ISSR amplifications also open new and interesting possibilities in the phytoplankton characterization field. In the future, the use of ISSR should be enlarged, for example, 1) for Harmful Algal Bloom monitoring by species identification of isolated cells, 2) to study genetic relationships among more species and genera to compare results with all the previous data, 3 ) to the management of species collections especially for strains identification or genetic stability (detection of somaclonal variations), 4) to creen quickly the most abundant SSR motifs in order to develop microsatellite markers. 


\section{Acknowledgements}

The authors thank V. Séchet, P. Lassus, V. Trenkel and D. Hervio-Heath for their help and comments on this manuscript.

\section{References}

Adachi M, SakoY, Ishida Y (1997) Analysis of Gymnodinium catenatum (Dinophyceae) using sequences of the 5.8S RDNA-ITS regions and random amplified polymorphic DNA. Fish. Sci., 63: 701-707.

Bolch CJS, Blackburn SI, Hallegraeff GM, Vaillancourt RE (1999) Genetic variation among strains of the toxic dinoflagellate Gymnodinium catanatum (Dinophyceae). J. Phycol., 35: 359-367.

Bornet B, Branchard M (2001) Nonanchored Inter Simple Sequence Repeat (ISSR) markers: reproducible and specific tools for genome fingerprinting. Plant Molecular Biology Reporter, 19: 209-215.

Bornet B, Muller C, Paulus F, Branchard M (2002) High informative nature of Inter Simple Sequence Repeat (ISSR) sequences amplified with tri- and tetra-nucleotide primers from cauliflower (Brassica oleracea var. botrytis L.) DNA. Genome 45: 890-896.

Chesnick JM, Morden CW, Schmieg AM (1996) Identity of the endosymbiont of Peridinium foliaceum (Pyrrhophyta): analysis of the rbcLS operon. J. Phycol., 32: 850-857.

Coyne KJ, Hutchins DA, Hare CE, Cary SC (2001) Assessing temporal and spatial variability in Pfiesteria piscicida distributions using molecular probing techniques. Aqua. Microb. Ecol., 24: $275-285$.

Devarumath RM, Nandy S, Rani V, Marimuthu S, Muraleedharan N, Raina SN (2002) RAPD, ISSR and RFLP fingerprints as useful markers to evaluate genetic integrity of micropropagated plants of three diploid and triploid elite tea clones representing Camellia sinensis (China type) and C. assamica ssp. assamica (Assam-India type). Plant Cell Rep. 21: 166-173.

Galvan MZ, Bornet B, Balatti PA, Branchard M (2003) Inter simple sequence repeat (ISSR) markers as a tool for the assessment of both genetic diversity and gene pool origin in common bean (Phaseolus vulgaris L.). Euphytica 132: 297-301.

Guillard RRL, Ryther JH (1962) Studies on marine planktonic diatoms. 1 Cyclotella nana Hustedt and Detonula confervacea (Cleve) Gram. Can. J. Microbiol., 8: 229-239.

Guillou L, Nézan E, Cueff V, Erard-Le Denn E, Cambon-Bonavita MA, Gentien P, Barbier G (2002) Genetic diversity and molecular detection of three toxic dinoflagellate genera (Alexandrium, Dinophysis, and Karenia) from French coasts. Protist 153: 223-238. 
Jaccard P (1901) Etude de la distribution florale dans une portion des Alpes et du Jura. Bull Soc Vaudoise Sci, nat 37: 547-579.

Lundholm N, Daugbjerg N, Moestrup O 2002. Phylogeny of the Bacillariacea with emphasis on the genus Pseudo-nitzschia (Bacillariophyceae) based on partial LSU rDNA. Eur. J. Phycol., 37: 115-134.

Murayama-Kayano E, Yoshimatsu S, Kayano T, Nishio T, Ueda H, Nagamune T (1998) Application of the random amplified polymorphic DNA (RAPD) technique to distinguishing species of the red tide phytoplankton Chattonella (Raphydophyceae). J. Ferm. Bioeng.ng 85: $343-345$.

Nagaoka T, Ogihara Y (1997) Applicability of inter-simple sequence repeat polymorphisms in wheat for use as DNA markers in comparison to RFLP and RAPD markers. Theor Appl Genet 94: 597-602.

Oldach DW, Delwiche CF, Jakobsen KS, Tengs T, Brown EG, Kempton JW, Schaefer EF, Bowers HA, Glasgow HB, Burkholder JM, Steidinger KA, Rublee PA (2000) Heteroduplex mobility assay-guided sequences discovery: elucidation of the small subunit (18S) rDNA sequences of Pfiesteria piscicida and related dinoflagellates from complex algal culture and environmental sample DNA pools. Proc. Natl. Acad. Sci. USA,97: 4303-4308.

Provasoli L (1968) Media and prospects for the cultivation of marine algae. pp. 63-75. In Watanabe A, Hattori A (eds) Cultures and Collections of Algae. Proc. U.S.-Japan Conf. Hakone, Japan, September 1966. Publ. by the Jap. Soc. Plant Physiol.

Rohlf M (1998) NTSYS-pc, numeral taxonomy and multivariate analysis system. Version 2.0. Department of ecology and evolution. State University of New York.

Scholin CA, Herzog M, Sogin M, Anderson DM (1994) Identification of group- and strainspecific genetic markers for globally distributed Alexandrium (Dinophyceae). II. Sequence analysis of a fragments of the LSU rRNA gene. J. Phycol. 30: 999-1011.

Scholin CA, Marin R, Miller PE, Doucette GJ, Powell CL, Haydock P, Howard J, Ray J (1999) DNA probes and a receptor-binding assay for detection of Pseudo-nitzschia (Bacillariophyceae) species and domoic acid activity in cultured and natural samples. J. Phycol., 35: 1356-1367.

Takishita K, Uchida A (1999) Molecular cloning and nucleotide sequence analysis of psbA from dinoflagellates: origin of the dinoflagellate plastid. Phycological Research, 47: 207-216.

Uribe PC, Suarez-Isla BA, Espejo RT (1999) Ribosomal RNA heterogeneity and identification of toxic dinoflagellate cultures by heteroduplex mobility assay.J. Phycol., 35: 884-888. 
Walsh D, Reeves RA, Saul DJ, Gray RD, MacKenzie L., Bergquist D, Bergquist PL (1998) Heterogeneity of SSU and LSU rDNA sequences of Alexandrium species. Biochem. Syst. Ecol.26: 495-509.

Zietkiewicz E, Rafalski A, Labuda D (1994) Genome fingerprinting by simple sequence repeat (SSR)-anchored polymerase chain reaction amplification. Genomics 20: 176-183. 